\title{
CONDITIONS AND BARRIERS TO SCHOOL INCLUSION FOR CHILDREN WITH FETAL ALCOHOL SPECTRUM DISORDERS - FASD
}

\author{
Petra Mitašíková, PhD. ${ }^{1 *}$, Barbora Vodičková, PhD. ${ }^{2}$ \\ 1Dr., Slovakia, petra.mitasikova@gmail.com \\ 2Dr., Slovakia, barbora.vodickova@gmail.com \\ ${ }^{*}$ Corresponding author
}

\begin{abstract}
The text theoretically defines fetal alcohol spectrum disorders (FASD) and their causes, describing FASD as a spectrum including specific diagnoses with typical symptomatology and impacts on the individual's school functioning and eco-system. This study investigates inclusive conditions in school environments for children with FASD. Based on qualitative research through the research method of "thematic analysis", it provides an in-depth analytical probe into the situation of children with fetal alcohol syndrome (FASD) and their families in the process of compulsory school attendance in Slovakia. The qualitative research aimed to find out where guardians/parents of children with FASD see positive sources of support and opportunities for their children's inclusive acceptance in the school environment and, on the other hand, where they identify barriers and obstacles). Positive sources of school inclusion for the child with FASD in according to caregivers/parents of these children included: The importance of knowing the FASD diagnosis; The use of alternative teaching approaches for the child with FASD in the school setting; Finding positive reserves in the child with FASD; and $A$ welcoming attitude from educators in the school setting. These factors significantly helped the children function in the school environment and participate in school life. On the contrary, we from interviews identified the following as barriers to school inclusion of the child with FASD: Developmental difficulties in the child with FASD; Unproportional academic performance in the child with FASD; Eco-systemic barriers to the child with FASD; Institutional exclusion of the child with FASD. This paper is a partial output of the Kega project 002UK-4/2020 Supporting a child with sensory processing disorder through a multisensory environment.
\end{abstract}

Keywords: Fetal Alcohol Spectrum Disorders - FASD, school inclusion, narrative interview

\section{INTRODUCTION}

Interest and awareness of fetal alcohol spectrum disorders (FASD) are increasing worldwide. The issue of binge drinking is a growing concern across countries worldwide. Drinking in women has particularities, especially in pregnancy, with a possible lifelong impact on the child. There is no safe level of alcohol consumption for pregnant women, nor is there a specific period of pregnancy that does not put the developing foetus at risk. The lifelong consequences in the future will be borne by the child itself and the child's family and surroundings. Their quality of life will be impaired in many areas - both physical and psychological, and social. This is a preventable disease and disorder on the FASD continuum, and therefore special attention needs to be paid to prevention and education. The problem of FASD is worldwide and is therefore increasingly coming to the attention of international research teams and professional associations that represent professionals, parents and individuals affected by FASD themselves. 


\section{DEFINING FETAL ALCOHOL SPECTRUM DISORDERS (FACD) AND CONTEXTS OF INCLUSION}

\subsection{Definition and Aetiology of Fetal Alcohol Spectrum Disorders (FASD)}

Fetal Alcohol Spectrum Disorders (FASD) is an umbrella term covering a group of congenital neurodevelopmental defects and brain damage resulting from prenatal alcohol exposure (PAE) (Astley, 2004). Although human research has not been able to delineate the amount of alcohol during pregnancy or the critical prenatal period of fetal alcohol exposure causing structural and/or functional teratogenesis, animal studies have demonstrated that all stages of an individual's prenatal development are susceptible to the teratogenic effects of alcohol (Wilson and Cudd, 2011). Animal studies also show that even small amounts of alcohol during pregnancy can lead to brain dysfunction and subsequent behavioural abnormalities (Lange et al., 2017). Risk factors associated with the development of FASD include: a woman over the age of 30, having a long history of drinking alcohol, poor maternal nutrition, having already given birth to one child with FASD, genetic susceptibility in a woman to slow alcohol metabolism (Vorgias and Bernstein, 2021). Lange et al. (2017) list four diagnostic entities within FASD (FAS, pFAS, ARND, ARBD). Alcohol during maternal pregnancy can affect any organ or system in the developing fetus, and individuals with FASD may have a wide range of comorbidities in any of the chapters Q18 to Q22, according to ICD10 (Lange et al., 2017; ICD10, 2021). According to Stade et al. (2006), the term Fetal Alcohol Effects (FAE) and the more recent terms pFAS, ARND, and ND-PAE have also been used to describe cases of minor severity in the context of cognitive function and facial and/or organ abnormalities (ibid).

\subsection{Diagnosis of FASD}

Worldwide, there are several approaches to diagnosing disorders associated with prenatal alcohol exposure during pregnancy. Although similar in many respects, there are differences in diagnostic criteria, terminology, methods of documenting the presence of PAE, and thresholds to determine growth impairment and neurodevelopmental disorders (Bower et al., 2020). This is a complex procedure and requires a holistic and multidisciplinary diagnostic assessment (FASD: Assessment and diagnosis). Riley et al. (2011) list four commonly used diagnostic schemes for FASD that include the presence or absence of these deficits in the diagnosis - prenatal and/or postnatal growth deficits; CNS dysfunction and characteristic facial anomalies and in some, PAE is also detected and ruled out. These include, according to Riley et al. (2011): the 4-Digit Diagnostic Code (Susan Astley, 2004); the National Task Force/CDC (Bertrand et al., 2005); the Canadian Guidelines (Chudley et al., 2005); and the Revised IOM (Hoyme et al.,2005).

\subsection{Neurocognitive and Behavioural Profile of Children with FASD}

Most children diagnosed with FASD exhibit some combination of neuropsychological and behavioural problems. These children are often mislabeled as having disorders such as Attention Deficit Disorder (ADD) because they have similar behavioural impairments (Zieff et al., 2016). The above highlights the importance of accurate differential diagnosis. Children with FASD show reduced intellectual function, with average IQ scores ranging from borderline to low average. Slow information processing and attentional impairments in individuals with FASD have been observed from childhood through adulthood. Clinical and experimental reports of individuals with FASD document significant deficits in executive functions, particularly in tasks involving the storage and manipulation of information in working memory. Studies examining specific areas of cognitive function such as language, visual perception, memory and learning, social functioning, and number processing in individuals with FASD have revealed performance decrements associated with increased task complexity. These findings are consistent with the conclusion that children with FASD have a general deficit in information processing and integration (Kodituwakku, 2009). Individuals with FASD exhibit differences in problem behaviors ranging from hyperactivity and aggression to social problems in interactions with peers, school attendance, and later maintaining stable employment (Center for Substance Abuse Prevention - US, 2014). (Center for Substance Abuse Prevention - US, 2014). Severe PAE has been associated with significantly more childhood sleep problems and a higher likelihood of reporting persistent sleep problems than children without PAE (Chandler-Matrher et al., 2021). Many children with FASD are also diagnosed with comorbidities such as ADD/ADHD (Zieff et al., 2016).

\subsection{Pupils with FASD in the School Environment}

Children with FASD have difficulty understanding the connections between their behaviour and the consequences of their actions (Brown and Mather, 2013). Capakova et al. (2021) recommend working for the improvement of motor skills, communication, behaviour, attention, sensory perception, social skills, adaptation, spatial and temporal orientation, school readiness and the development of each child's 
uniqueness within the framework of the inclusion of pre-school children. Zieff et al. (2016) state that teachers are often puzzled by the difficult to grasp and sometimes unexpected behaviours and learning difficulties that these pupils exhibit. Working with these pupils can be frustrating and discouraging. Teachers find traditional learning methods and standard teaching practices ineffective for students with FASD. These students want to please their teachers but end up feeling like failures. There is a lack of broader awareness and understanding of FASD in society. These often unidentified students are therefore misunderstood. The lack of success of these students with FASD has been attributed to many other proxy reasons (Zieff et al., 2016). According to Brown and Mather (2013), when raising and educating a child with FASD, it is essential to have information about FASD and be mindful of increased communication with the school. According to the authors (ibid), school is a significant challenge for both the child and the parents. It mainly touches on three areas: 1 . The child struggles with the curriculum. For children with FASD, a significant challenge is the area of mathematics, with which they have significant difficulty. 2. School is usually a less structured environment, disproportionate to a child with FASD. 3. The social aspect of school life is also an enormous burden for the child. FASD can affect 3 to $5 \%$ of school-aged children enrolled in mainstream education, with many remaining undiagnosed (May 2014).

\subsection{Creating Inclusive Environments for Children with FASD}

The Slovak Republic has adopted the UN Convention on the Rights of Persons with Disabilities, which implies a commitment to access quality education at all levels for children with disabilities on an equal basis with others (UN General Assembly, 2006). Danz (2019) stresses that inclusion does not mean paying attention to some children (so-called "Inklusionskinder"). It is not about integrating certain children but about achieving a common education for all children. Inclusive education can be understood as a process in which all children are educated together in mainstream education, regardless of their social, cultural, linguistic, intellectual or health disadvantages (differences). Although there is already widespread support for inclusion at a philosophical and application level. Horńáková (2017) states, that inclusive communication is characterised by respect, openness, seeking solutions and creating opportunities for participation. Rouse (2008) points out in his work that there is some concern that inclusion policies are challenging to implement because teachers are not sufficiently well prepared and supported to work inclusively. Inclusion requires policymakers, principals and teachers to create schools where all children can learn and feel that they belong. According to Janosko (2020), an inclusive school seeks to know and purposefully use its internal and external resources, identify barriers to inclusion and reduce them. It is not only about removing physical barriers but also about increasing teachers' competence and readiness for inclusive forms of learning and collaboration Florian (jn2007). The author examined how teachers can respond to differences between children, how they can include all children in the educational process instead of excluding the 'less able', whether and how they can respond flexibly to what is happening in the classroom, whether they can adapt the range of educational resources to what is commonly available within the classroom. An inclusive school needs to explore its internal and external resources to make the best use of them in the educational process (ibid).

\section{QUALITATIVE RESEARCH}

\subsection{Methodology}

We used a qualitative methodology in this research. According to Gavora (2006), it aims to reveal how people interpret the world. An inductive approach is prevalent in qualitative research, moving from data to theory. Each individual or group study is a unique case for the researcher. Generalization is only possible if it relates to other individual cases that have been deeply, comprehensively, and/or intensively researched. Silverman (2005) recommends using qualitative methods when researchers choose to investigate people's life histories. The methods given can convey a 'deeper' understanding of social phenomena. They prefer analysis of words rather than numbers; observation over experiment; unstructured observation/interview rather than structured; meanings rather than descriptions of behaviour and inductive linked research rather than deductive.

\subsection{Research Aim and Research Questions}

The research aimed to explore where caregivers/parents of children with FASD see positive sources of support and opportunities for their children's inclusive acceptance in the school environment and, on the other hand, where they identify barriers and obstacles. We formulated the following research questions.

\section{What are the positive resources to inclusive acceptance of a child with FASD in a school setting?}


2. What are the barriers and obstacles to creating an inclusive environment in the school setting for a child with FASD?

\subsection{Research Set}

The research sample consisted of 7 families (or seven parents). Their selection was deliberate. The inclusion factors were: family with a child with a diagnosed FASD, age of the children from 7 to 18 years.

\subsection{Methods of Data Collection and Processing}

Data collection was conducted through narrative interviews with 7 participants. In multiple sessions, caregivers/parents told the researchers their life stories with their child with FASD.

- The data collected from the interviews were transcribed into written form.

- The transcribed qualitative data was then broken down into separate meaning units. We assigned a numerical code to each unit of meaning.

- The transcripts thus numerically coded were ready for ongoing analysis. The researchers analyzed each coded meaning unit. The objectively observed data were interpreted and labelled through margin notes. The notes delineated the content of the research participants' statements and the observed facts.

- Subsequently, we proceeded to categorize the analyzed data on an ongoing basis. We sorted it into common second-order categories.

- We then divided the second-order (lower-order) categories into first-order (higher-order) categories.

- Based on the data collected, transcribed, continuously analyzed, and interpreted, we formulated four themes related to "Positive sources of school inclusion of a child with FASD" and four to "Barriers to school inclusion for the child with FASD".

\subsection{Limits}

A research limitation was the limited number of participants (7 families) out of the 20 interviewed. Only one research method (narrative interview) was used to collect data. We did not have the opportunity to participant observe and compare the data thus obtained with the real situation in the families.

\subsection{Research Results}

Within the qualitative research, we formulated two main categories - themes that relate to the issue of school inclusion of a child with FASD. Within the first category - the theme named: 'Positive sources of school inclusion of the child with FASD', we identified four sub-themes. Within the second category, the theme named: "Barriers to school inclusion of the child with FASD", we also identified four sub-themes. We list them as follows:

\section{Positive sources of school inclusion of a child with FASD}

1.1 The importance of knowing the diagnosis of FASD

1.2 The use of alternative teaching approaches for the child with FASD in the school environment

\subsection{Finding positive reserves in the child with FASD}

1.4 An accepting attitude on the part of educators in school settings

\section{Barriers to school inclusion for the child with FASD}

\subsection{Developmental difficulties in the child with FASD}

1.2 Unproportional academic performance in the child with FASD

\subsection{Eco-systemic barriers to the child with FASD}

\subsection{Institutional exclusion of the child with FASD}

We specify the different second-order categories in the following and give examples from the interviews. Each example has a numerical code (the first number denotes the meaning unit, and the second the number of the interview).

\section{Positive sources of school inclusion for the child with FASD}




\subsection{The importance of knowing the diagnosis of FASD}

All parents found it a relief to learn their children's accurate diagnosis after often long years of groping and uncertainty. They informed the school authorities where their children with FASD were placed. The question was to what extent the school authorities understood the FASD and accepted the child with FASD in that school. Children thrived better in schools that were willing to accept the limitations and possibilities of the FASD and adapt the environment and teaching methods accordingly. It was beneficial if the school was informed in advance about the specifics of both the FASD diagnosis and the child's individual capabilities. It appeared to be significantly helpful if the child had the opportunity to have support from a knowledgeable teaching assistant directly in the classroom. Parents were compelled to self-educate about FASD to create better conditions for their children. Children thrived well if their individual specifics were taken into account (e.g., the need to go to a room where the child can calm down when upset, explain the material one-on-one, write a test in a separate room, allow the child to move from a place within or outside the classroom).

Examples from interviews: $27.1 \mathrm{M}$ : "This diagnosis occurred in the third month after starting primary school. We finally knew how to name it as parents." $133.4 \mathrm{M}$ : "After the FAS diagnosis, the special education counselling centre recommended integrating Emma in school for medical reasons. "134.4 M: "Further examinations at the special education counselling centre (after moving) diagnosed her with multiple learning and attention disorders, and an aide was recommended." 126.4 M: "This resulted in a diagnosis of code 4443." (Astley code) 128.4 M: "After the diagnosis, I understood Emma's problems and tried to reflect this in her care." 34.5 M: "At that time, we came across the possibility of a diagnosis of FASD. Although the confirmation of FASD took us by surprise as parents, on the other hand, it opened our eyes, and we were able to change our approach to our child."

26.6 M: "I have prepared an info booklet The child from a foster family in school." 43.7 M: "In February in Year 1 she was diagnosed with FAS, the class teacher knew the diagnosis, we discussed it with the special education teacher and referred her to the special education counselling centre for assessment - where the worker assessed that if she was to assess her based on her performance - there was no problem - she can write, she can read, she can do arithmetic, but in view of her other problems and FAS she suggested an individual education plan which is still being followed." 47. 7 M: "We are very happy with the choice of school, especially from a special education point of view, my daughter's condition is taken into account when assessing her not only in academic performance but especially in behaviour, she has the opportunity to leave the classroom during the lesson, she has had an assistant since year three - in year three it worked best - she was proud of herself, relatively good results at school - the assistant took her to different environments for tests, or she explained the material separately if there was something to emphasize, in maths she had more mechanical tasks, less essay examples. "

\subsection{Using alternative teaching approaches for the child with FASD in the school environment}

Parents communicated that the child benefited from being freed from writing in cursive with the alternative of writing in Comenius script (a unique print font). They were positive if the teacher approached the child through fun and interesting activities (e.g., art, work, creative) that did not rely on details but allowed the child to succeed. The low-impact environment and stable school and home routines were particularly reassuring. Children thrived better in smaller school groups. An individualized approach - one to one - helped several children. Often parents had to contribute financially to provide tutoring for the child through a private tutor. Even when a child was given 'integrated child' status at school and an individual education plan was drawn up, it was rarely followed in frontline teaching. Parents were looking for receptive teachers willing to listen and agree to alternative approaches towards the child, which the parents suggested based on their experiences with homeschooling. Paradoxically, both children and parents were relieved during the lockdown on online learning because children did not have to manage academic goals along with social and emotional ones. This combination overwhelms children with FASD tremendously. They often showed signs of inattention and memory problems in school because of the emotional overload. The children benefited greatly from an individualized approach within the classroom to the detriment of group and team teaching methods. Abbreviated lessons proved to be very beneficial, as children with FASD find being in a dynamic group of other children for long periods extremely overwhelming. Parents reported that the smaller school group and shorter lessons were helpful for these children. These children also need a teaching assistant in the classroom as they show great difficulties in independence, self-management, especially in multi-step tasks. Possitive was if the teaching assistant could respond well to the child's needs (e.g., when overloaded, they went together to a special room where he or she explained the material to the child or where the child could write a test in peace). Parents reported that as the demands at school escalated, children had increasing difficulty coping with the demands as they progressed to higher grades. They appreciated if the 
child was allowed concessions, e.g. shorter papers, modified assessments, and the possibility of writing tests in a different - special room. Parents also mentioned possibility and advantages homeschooling to follow the child's rhythm and adapt individually to his/her capabilities and needs. Children with FASD thrived better in homeschooling than in a busy school.

Examples from interviews: $32.1 \mathrm{M}$ : "What saved us at this school was that they wrote more or less in print - they used Comenius script. That saved him because he had a big problem with writing." $48.1 \mathrm{M}$ : "There in the third grade they did much creating all sorts of things and Mato liked that a lot and that teacher was able to grab Mato, to get to him through his interest and Mato loved that creation. The teacher was very calm; he did not dwell on details, although the classroom, which was not very optimal for Mato, was very overdecorated." $54.1 \mathrm{M}$ : "Regarding this private school with a minority language of instruction, the school gave us the condition that Mato would be educated individually (one-on-one) within the school. So I agreed. For the subjects that were not sufficiently staffed for Mato's individual education, we helped to provide tutoring through a private line. That is how we pulled it off this year." $56.1 \mathrm{M}$ : "Structured, clean, white classroom, high structure, fixed schedule, fewer kids, strict teacher." 67.1M: "I would also suggest some concessions, e.g. shortening the length of the class, because the child gets tired more and quicker, which is automatically followed by a deterioration in behaviour, and this would prevent that." 35.2 M: "Paradoxically, covid and online tuition helped us." 135.4 M: "Since the last school year (7th grade), on the recommendation of the child psychiatrist and subsequently the private special education counselling centre, he has had his classes shortened to four hours a day. She has an assistant, an Individual Education Plan." 154.4 M: "She also gave her a separate desk for her classroom, which Emma is happy with." 171.4 M: "She was more comfortable with distance education; she evaluated it that way herself." $26.5 \mathrm{M}$ : "In the end, we decided not to place the child in a mainstream school, and homeschooling became our choice."

\subsection{Finding positive reserves in the child with FASD}

Parents communicated that it is useless to push for performance in subjects the child is not good at. Without this pressure, the child's behaviour also improved, and his confidence increased. It is inappropriate to constantly and unilaterally talk only about the child's problems and negatives (in front of the child and the parents). It is impossible to achieve constructive cooperation without balanced communication on how to overcome difficulties or constantly notice and appreciate even small positive signs in the child's learning and behaviour. The teacher is also required to look for the positive side of the child's difficulties - for example, to dont see the problem in too much mobility but the possibilities hidden in it. It is necessary to be sensitive to any signs of self-depreciation in the child and to offer him to see himself in a 'different mirror' in order to gradually modify his self-image from a negative to a positive one (as prevention of possible psychological problems, disorders resulting in self-harm or suicidal thoughts).

Examples from interviews: $66.1 \mathrm{M}$ : "And the most important thing is not to always talk only about the problems, because that stresses not only the child but also us parents, but to build on the positives." 91.4 M: "She is very fond of small children - she is sensitive to them, she always wanted a baby, a sibling, we have to go to the Children's Home to get him, she wanted us to find a daddy too." 93.4 M: "At the moment, she is friends with children in her age group, but also with younger and older ones as long as they match her mental level." 180.4 M: "Emma rates herself as ugly, mean and nasty, although I try to praise her, encourage her and show what she has done, what she can do (e.g. she can relate well manage with young children, she can engage them, she can play with them, she can bake muffins, she can groom herself nicely and paint herself delicately. ..)" 68.5 M: "We bought him an old car (he was only ten years old at the time), he learned how to take it apart and put it back together, he had the whole engine disassembled, he connects circuits, he knows how to weld. This week a friend gave him a second car. He is thrilled. He knows how to drive it. This is his world, what he likes, and what he knows. So hopefully, one day, he will be able to make a living at it. Finding and building on a child's positive reserves!" $41.6 \mathrm{M}$ : "He is friendly, kind, empathetic, responsive, joyful, grateful, enjoys life, interested in people, immediate family." $23.7 \mathrm{M}$ : "She is very social, intensely experiencing other children, we went to the parent centre for games and singing moms and kids."

\subsection{An accepting attitude on the part of educators in school institutions}

Parents reported that it helped the child and them a lot if the attitude of the teacher was to give it a try with the child and was not immediately dismissive at first. A teacher who was able to introduce some structure and predictability was also helpful to the child. Equally, the attitude of the school management was very crucial. An attitude of acceptance of each child and a 'let us give it a go' attitude. In particular, the accepting class teacher who discovered positive reserves and resources in the child played a significant role. Teachers who understood that it was useless to be based on details, push for performance at any cost, and balance criticism with strategies based on encouragement were particularly helpful. They also appreciated the 
attitude of the school management, which did not allow other parents from the class to interfere in dealing with the child's situation with FASD. School management and the class teacher have to stand up for the child with a disability at some point. For example, to deal with bullying situations, exclusion of the child within the pupil groups - not to agitate the psychodynamic situation in the classroom. It also seemed necessary to know the child more deeply from the psycho-social side - not only from the academic side on the part of teachers. Empathetic communication between school institutions and parents was helpful. Not only pointing out the child's negatives - but also its sources - and finding ways out and overcoming difficulties together with the parents.

Examples from the interviews: $46.1 \mathrm{M}$ : "The teacher told me he would try it with him." $60.1 \mathrm{M}$ : "Only finally the only mainstream primary school, or its headmistress, told me, despite the information about Mato, that she would take him, that she dared to do it." 61.1 M: "So he did his 8th-9th grade at this elementary school where he had a great class teacher, and she helped bring out his positives and potential. Mato has been in a drama club - theatre - since he was a little boy and this class teacher ensured that the whole class went to see one of his performances. It made Mato rise in the children's eyes, suddenly the children saw him in a different light, that he could do something special and it helped his acceptance among the other children." $60.3 \mathrm{M}$ : "The next day, I was approached by the headmistress of the kindergarten; she already knew about the organized plot against my son." 61.3 M: "She said that they are a facility for all children, my son is not aggressive, and no parental exclusion will take place." $153.4 \mathrm{M}$ : "Things are better at the moment. The approach of the headteacher, who repeatedly spoke to Emma, tried to listen, guide and help her, has contributed to the improvement. I talked to the headteacher about it, and she then told Emma that she would not just let her out of school because she likes her." $155.4 \mathrm{M}$ : "I cannot rate the cooperation with the school as bad. They have tried and are trying to be considerate of Emma's FAS and mental state."

\section{Barriers to school inclusion of a child with FASD}

\subsection{Developmental difficulties in the child with FASD}

The category describes difficulties observed by parents from the child's early years in the following areas of development: sensory hypersensitivity (e.g., difficulty eating); social-emotional problems (e.g. neuroticism, anxiety, difficulty coping with change, low self-confidence, self-harm, quickly tired, bedwetting, tantrums, hurting others - especially parents, other children, but also self-harm); cognitive difficulties (e.g. attention, memory, sequencing of steps - seriality, delayed speech development); problems in motor area (e.g. hyperactivity, impaired fine motor skills).

Examples from interviews: $39.4 \mathrm{M}$ : "Internal tension was manifested by biting her fingernails, which persists until now (she also tended to bit her feet, I managed to stop it, last months she started again)." 25.2 M: "She is afraid of everything new." $41.4 \mathrm{M}$ : "I was able to eliminate the bedwetting (even at night) at the age of four and a half years before starting kindergarten." $15.5 \mathrm{M}$ : "He had a hard time with change, was very excitable, hard to calm down." $16.5 \mathrm{M}$ : "He was difficult to adjust socially around children, occasionally hurt other children." 9.6 M: "Temper tantrums from a young age, manifested by escalating crying." 17.1 M: "Reports came from preschool that he would not sit still, run, not listen, not concentrate. "44.1 M: "Did not draw systematically, not concentrated - but would grab paper and scribble, tear."

\subsection{Unproportional academic performance in a child with FASD}

The category describes the performance disparity across school subjects resulting from impairments and from unproportional in cognitive functions (perception, attention, memory, thinking, speech). Problems are particularly evident in solving logic problems (deficits mainly in the non-verbal component of IQ). Interconnection of problems in the cognitive domain with impairments in fine motor skills (dislike of fine motor activities such as drawing, writing and corresponding impatience in performing them, lack of concentration). These fluctuations are particularly noticeable in school, where learning conditions are difficult for children with FASD. Research has highlighted the resignation of parents and teachers in achieving optimal performance in particular subjects. To avoid punishment (e.g., a bad grade, a poor evaluation), children were "forced" to lie to conceal facts. The child's increased fatigability in intellectual work resulted in defensiveness and aversion to intellectual work. Problems also emerged in the context of executive functions (planning, working memory, impulse control, inhibition - dampening of distracting stimuli, mental flexibility, initiation initiation and monitoring of activity).

Examples from interviews: $34.1 \mathrm{M}$ : "However, the big problem was in mathematics. Abstract concepts did not tell him anything and still do not today. He still has problems, e.g. orientation in time, hours, seasons, months, money management. Alternatively, he asks me, now in September, when are we going to buy clothes for spring. He is lost in this. "35.1 M: "He has a problem, especially in sequences (in seriality). So far, 
he is lost in it." 40.1 M: "He has a big difference in IQ. Verbally he is slightly above average. Moreover, nonverbally he is well below average. Furthermore, this also makes a problem. This disparity." 28.2 M: "For a long time, she could not memorize letters." 29.2 M: "She counted on her fingers for a long time." 79.3 M: "He was making quite a bit of progress, but when it was something with logical thinking, already hints of math, there was nothing he could do at all." 93.3 M: "He started to bring terrible grades; the worst were dictations, five-minute tests and papers in English and mathematics." $116.3 \mathrm{M}$ : "That was because he showed me other material to learn that was written on one page, just to avoid learning the material that was on three pages." 162.4 M: "She also forgets things related to daily functioning - e.g. which is her towel, toothbrush, she forgets to take off her socks when she goes to shower, she only gets some of her things ready for school, she forgets to take her workbook or book from the subject." 169.4 M: "Sometimes I feel like Emma cannot finish these last two years of primary school. It is extremely difficult for her to go to school, learn the curriculum, and live-in relationships with her classmates and teachers. "38.5 M: "The biggest problems have been with math."

\subsection{Eco-systemic barriers to the child with FASD}

The category defines the creation of deliberate barriers and obstacles towards the child with FASD (at the level of teachers, principals, assistants, other parents, classmates) that emotionally hurt both the child and his/her parents. The barriers erected prevented the child and his/her family from participating in mainstream life (school, community, playgroups). The child was excluded not only from school but also from extracurricular activities. The child was thus prevented from gaining typical childhood experiences. There were insurmountable barriers to inclusive acceptance. Ordinary catchment schools struggled to accept a child with difficulties and provide adequate support and specialist help. The child faced rejection, even bullying and ridicule among peers. Educators from the school communicated outwardly to the parents that the child was challenging to work with.

Examples from interviews: 29.1 M: "The assistant has gradually built up an imaginary wall against Mato, so she communicated that to me as a mother, that for her is important somehow to survive with Mato. Moreover, that touched me as a mother; it hurt me." $53.1 \mathrm{M}$ : "The catchment school had already made us feel when we were talking about his admission that Mato was not going to be supported in any way at the school and we felt that it was not going to be good there, that Mato was not going to make it because of that attitude. $3 \mathrm{M}$ : "A colleague told me that the parents of the kindergarten children are going to meet and will demand that my son be transferred from the kindergarten. $177.4 \mathrm{M}$ "In the lower grades, some of her classmates taunted her that she was mean because she was integrated." $20.5 \mathrm{M}$ : "At the age of 5.5, he started kindergarten for half a day. Teachers reported that he was disruptive, not concentrating; the children looked at him as the one who was always disrupting and being the 'bad boy'." 52.5 "Always with the new school year approaching, we tried to approach different schools to see if they would accept our child. We approached a school for children with autism, two schools for children with hearing impairment. Although they were initially helpful and even called us to the school, in the end, they did not accept us "because of lack of space" or because our diagnosis did not fit their focus."

\subsection{Institutional exclusion of the child with FASD}

This category describes forms of institutional exclusion of the child, mainly by school institutions. Much pressure was put on the parents of the child with FASD. The school environment did not understand the needs and expressions of a child with this severe disability and a difficult, traumatic past. FASD is not visible at first glance or well visible to the surroundings. What was evident were disruptive behavioural manifestations and learning difficulties that could be disruptive, burdensome, and sometimes even threatening to those around her. Often, even professionals (e.g. teachers in the school) who would be expected to manage even more challenging behaviour and learning difficulties could not cope with the child. Children with FASD and their parents alluded to the inability of schools to deal with children with behavioural and learning difficulties. The consequence was experiencing repeated exclusion of the child from school institutions with a serious impact on the family overall. The parents tried their best to keep the child in the institution, which was very draining for the family (energetically, financially and logistically). The parents tried to support the child in various ways (tutoring, assistants, therapeutic interventions) to prevent further "failure" of the child and hurtful exclusion for him. Even the leisure activities could not cope with the demands of a child with FASD, and they too excluded him.

Examples from the interviews: $30.1 \mathrm{M}$ : "In the second grade, the school started to communicate whether they were the right school for Mato because there are too many stimuli at school, demands for teamwork (project-based learning in a team), the school is colourful, lively, overcrowded, and less structure, which the school thinks Mato would rather need the opposite. The school advised us to look for another school for 
Mato. And I could not handle the pressure of the school, and we left." $45.1 \mathrm{M} .:$ "In the third grade, he entered a small family-type school - a one-room schoolhouse - which was sort of homeschooling at the time, but with a small group of children and with an enthusiastic, qualified teacher. Here, however, he lasted only half a year. However, the teacher could not cope with him, and Mato had to leave there after half a year." 49.1M: "But unfortunately, in the fourth year, it broke down again because he got another teacher. He tried his best, but he could not grip Mato like that. Furthermore, it came to the point again that at the end of the fourth year, they called us to the school and told us that after the fourth year, Mato would have to leave their school because they were a private school and Mato was disturbing other children. I burst into tears because I wanted to keep him there at all costs (after so many transfers), and I did not even tell him the whole vacation. I did not know how to tell him that they did not want him here either, and they excluded him" 55.1 M: "At the end of the year, they told me that they were excluding Mato from this school as well, so I told my husband that we were both going to school. We aimed to keep him there at all costs not to face further exclusion. Nevertheless, we could not keep him there." $105.3 \mathrm{M}$ : "I said we put up with everything, and maybe he would find himself in that music, but when it did not work out, we cancelled. (dropping out of art primary school)" $22.5 \mathrm{M}$ : "At the end of the school year, we advised to look for a school other than the mainstream school for the child." 64.5 M: "One more thing about the circle activities. He started piano lessons, got kicked out." 65.5 M: "He went to gymnastics; they kicked him out."

\section{CONCLUSION}

FASD represents a combination of neuropsychological and behavioural problems that affect the daily functioning of these children and their parents (Zieff et al., 2016; Kodituwakku, 2009). Compulsory school attendance is an important part of the lives of children with FASD, which presents a significant challenge due to the nature of their difficulties. It is not only that the children themselves grapple with the learning content daily, but they have problems solving the social challenges at school (Zieff, 2016, Brown and Matter, 2013). Also, their teachers and parents are often baffled by the challenging behaviours and learning problems that these children exhibit. Some of these children are placed in mainstream and some in special schools. Given the UN Convention on the Rights of Persons with Disabilities, which the Slovak Republic has adopted (UN General Assembly, 2006), efforts are being made to place more and more of these children in mainstream schools and create inclusive conditions for them. We attempted to map parents' experiences of children with FASD with school inclusion through qualitative research. Among the positive sources of school inclusion for a child with FASD, we identified four factors contributing to inclusive acceptance for the specific children studied. We identified the factor of the importance of parents and the school institution's knowledge of the FASD diagnosis, the helpfulness of using alternative teaching approaches, identifying and building on the positive reserves in the child with FASD, and the helpful attitude of the educators in the school institutions also proved to be highly significant. On the other hand, through interviews with parents, we identified barriers and obstacles of the school institution from their perspective. Parents described the presence of developmental difficulties in the child with FASD, the unevenness of performance in the academic area (e.g., the subject of mathematics appeared to be very problematic). On the side of the school institution, parents pointed to eco-systemic barriers to the child with FASD (e.g., the emotional hurting of parents and child from the school, pressure from other parents, teachers, school management, and lack of sufficient professional help at school for the child with FASD) and pressure to exclude the child even from out-of-school facilities.

The research was supported by a grant Kega No. 002UK-4/2020 Supporting the child with sensory processing disorder through a multisensory environment.

\section{REFERENCE LIST}

Astley, S. J. (2004). Diagnostic Guide for Fetal Alcohol Spectrum Disorders: The 4-Digit Diagnostic Code Third Edition. Center on Human Development and Disability School of Public Health and Community Medicine University of Washington Seattle.

Bower, C. et al. (2020). Australian Guide to the diagnosis of Fetal Alcohol Spectrum Disorder (FASD). Australian Gowernment. Department of Health. https://www.fasdhub.org.au/contentassets/32961d4a5cf94de48ebcf985c34d5456/australian-guide-tothe-diagnosis-of-fasd all-appendices feb2020 isbn.docx.pdf 
Proceedings of INTCESS 2022- 9th International Conference on Education \& Education of Social Sciences

17-18 January 2022- Online Conference

Brown, J., Mather, M. (2020). Ako byt' rodičom diet'at'a s FASD. Bratislava : Fascinujúce deti, oz. Návrat, oz.

Center for Substance Abuse Prevention - US. (2014). Addressing Fetal Alcohol Spectrum Disorders (FASD). Rockville (MD): Substance Abuse and Mental Health Services Administration (US); (Treatment Improvement Protocol (TIP) Series, No. 58.) Executive Summary. https://www.ncbi.nlm.nih.gov/books/NBK344248/

Capakova, L. et al. (2021). Inklúzia - pestré activity pre deti. Bratislava Raabe. p. 203

Danz, S. (2019). Inklusive Bildung: Solidarität und Teilhabe am eigenen Lernen lernen. Heilpaedagogik.de, 34(4), 13-20.

FASD: assessment and diagnosis. In: Canada's mental health \& addiction network https://www.porticonetwork.ca/treatments/disorders-qr/fasd/fetal-alcohol-syndrome-disorderassessment-and-diagnosis

Florian, L. (2007): Reimagining special education, In: The Sage handbook of special education. London Sage, London, 7-20.

Gavora, P. (2006). Sprievodca metodológiou kvalitatívneho výskumu. Bratislava: Regent.

Horňáková, M. (2017). Inkluzívne posolstvá v komunikácii školy. In Janoško, P., Kušnírová, V. Inkluzívna škola a rodina. Bratislava : UK v Bratislave, 9-23.

Chandler-Mather, N. et al. (2021). An investigation of the link between prenatal alcohol exposure and sleep problems across childhood. Drug and Alcohol Dependence. 218 (1). https://doi: 10.1016/j.drugalcdep.2020.108412

Chudley, A. E., Conry, J., Cook, J. L., Loock, Ch., Rosales, T., LeBlanc, N. (2005). Fetal alcohol spectrum disorder: Canadian guidelines for diagnosis. CMAJ March 172 (5 suppl) S1S21; https://doi.org/10.1503/cmaj.1040302

ICD-10-CM CODE Q86.0. (2021). Fetal alcohol syndrome (dysmorfic). https://icdlist.com/icd-10/Q86.0

Janoško, P. (2020). Inkluzívne školské prostredie. In Janoško, P. a kol. (2020). Učiace sa spoločenstvo výzva pre inkluzívne vzdelávanie. Bratislava: Univerzita Komenského. S. 33-52.

Kodituwakku P., W. (2009). Neurocognitive profile in children with fetal alcohol spectrum disorders. Dev Disabil Res Rev. 15(3):218-24. https://doi: 10.1002/ddrr.73

Lange, S., Probst, C., Gme,I G., Rehm, J., Burd L., Popova, S. (2017). Global Prevalence of Fetal Alcohol Spectrum Disorder Among Children and Youth: A Systematic Review and Meta-analysis. JAMA Pediatr. 171(10):948-956. https://doi: 10.1001/jamapediatrics.2017.1919.

May, P. T. et al. (2014). Prevalence and Characteristics of Fetal Alcohol Spectrum Disorders. Pediatrics.134(5):855-866.https://www.ncbi.nlm.nih.gov/pmc/articles/PMC4210790/

Riley, E. P., Infante M. A., Warren K. R. (2011). Fetal alcohol spectrum disorders: an overview. Neuropsychol Rev. 21(2),73-80. https://doi: 10.1007/s11065-011-9166-x

Rouse, M. (2008). Developing Inclusive Practise : A Role for Teachers and Teacher Education. https://www.abdn.ac.uk/education/research/eitn/journal/46/

Stade, B.C., Stevens, B., Ungar, W.J. et al. (2006). Health-related quality of life of Canadian children and youth prenatally exposed to alcohol. Health Qual Life Outcomes 4, 81. https://doi.org/10.1186/14777525-4-81

Silverman, D. (2005). Ako robit' kvalitatívny výskum, Bratislava: Ikar.

UN General Assembly (2006). Convention on the Rights of Persons with Disabilities: resolution /adopted by the General Assembly, 24 January 2007, A/RES/61/106, available at: https://www.refworld.org/docid/45f973632.html

Vorgias, D., Bernstein, B. (2021). Fetal Alcohol Syndrome In: StatPearls [Internet]. Treasure Island (FL): StatPearls Publishing. https://www.ncbi.nlm.nih.gov/books/NBK448178/

Wilson, S. E., \& Cudd, T. A. (2011). Focus on: the use of animal models for the study of fetal alcohol spectrum disorders. Alcohol research \& health : the journal of the National Institute on Alcohol Abuse and Alcoholism, 34(1), 92-98. https://www.ncbi.nlm.nih.gov/pmc/articles/PMC3625987/ 
Proceedings of INTCESS 2022- 9th International Conference on Education \& Education of Social Sciences 17-18 January 2022- Online Conference

Zieff, C. D., Schwartz-Bloom, R. D., Williams, M. (2016). Understanding Fetal Alcohol Spectrum Disorders (FASD) A Comprehensive Guide for Pre-K-8 Educators. 2016 Understanding FASD-RISE @ Duke. https://sites.duke.edu/fasd/ 